\title{
The effect of different inflating volume on the measurement accuracy of the modified cuff pressure measurement method
}

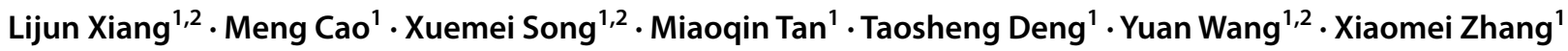

Received: 4 December 2020 / Accepted: 26 February 2021 / Published online: 11 March 2021

(c) The Author(s), under exclusive licence to Springer Nature B.V. 2021

\begin{abstract}
To evaluate the effect of different inflation volume on the measurement accuracy of the modified cuff pressure measurement method in different shapes of cuffs, so as to provide reference for the correct monitoring of cuff pressure in clinic. In vitro study: The traditional cuff pressure measurement method (the cuff pressure gauge before measurement shows $0 \mathrm{~cm} \mathrm{H}_{2} \mathrm{O}$ ) and the modified cuff pressure measurement method (the cuff pressure before measurement shows $25 \mathrm{~cm} \mathrm{H}_{2} \mathrm{O}, 28 \mathrm{~cm} \mathrm{H}_{2} \mathrm{O}$, $30 \mathrm{~cm} \mathrm{H}_{2} \mathrm{O}$ or $32 \mathrm{~cm} \mathrm{H}_{2} \mathrm{O}$ ) were used to measure cylindrical and tapered cuffs, and the effect of different inflation volume on cuff pressure was analyzed statistically. Clinical study: patients with the artificial airway established by orotracheal intubation or tracheotomy in Neuro-ICU were prospectively selected as subjects, and the measurement procedure was the same as in vitro study. In vitro study showed that the pressure loss values of cylindrical cuff and tapered cuff using the traditional cuff pressure measurement method were $(3.75 \pm 0.31) \mathrm{cm} \mathrm{H}_{2} \mathrm{O}$ and $(4.92 \pm 0.44) \mathrm{cm} \mathrm{H}_{2} \mathrm{O}$, respectively, and clinical study showed that the pressure loss values were $(5.07 \pm 0.83) \mathrm{cm} \mathrm{H}_{2} \mathrm{O}$ and $(5.17 \pm 0.93) \mathrm{cm} \mathrm{H}_{2} \mathrm{O}$, respectively. The actual measured values measured by the traditional cuff pressure measurement method of the two cuff shapes were compared with the corrected target value of $28 \mathrm{~cm} \mathrm{H}_{2} \mathrm{O}$, and the differences were statistically significant $(P<0.000)$. Both in vitro and clinical study had shown that all differences between the actual measured value and the corrected target value using the modified cuff pressure measurement method (measured with $\left.25 \mathrm{~cm} \mathrm{H}_{2} \mathrm{O}, 30 \mathrm{~cm} \mathrm{H}_{2} \mathrm{O}, 32 \mathrm{~cm} \mathrm{H}_{2} \mathrm{O}\right)$ were statistically significant $(P<$ $0.000)$, and the range of overall differences was $(0-1.23 \pm 0.25) \mathrm{cm} \mathrm{H}_{2} \mathrm{O}$. In vitro study had shown that the pressure variation coefficient $(\mathrm{CV})$ of the tapered cuff was greater than that of the cylindrical cuff, and the difference was statistically significant $(3.08 \pm 0.25 \mathrm{VS} 2.41 \pm 0.21, P<0.000)$. The traditional cuff pressure measurement method can directly lead to the cuff pressure drop, which is easy to cause the leakage of secretions on the cuffs and the misjudgment of the cuff pressure by medical personnel. However, the modified cuff pressure measurement method can effectively reduce cuff pressure loss, and taking the actual cuff pressure value as the inflation volume is the highest measurement accuracy.The tapered cuff is more susceptible to air volume, so it is necessary to pay attention to its measurement and correction in clinical practice.
\end{abstract}

Keywords Modified cuff pressure measurement method $\cdot$ Cuff pressure $\cdot$ Cuff shape $\cdot$ Artificial airway $\cdot$ Measurement accuracy

\section{Introduction}

Cuff management is an important part of artificial airway management. The guidelines $[1,2]$ recommend that the cuff pressure should be maintained at $25-30 \mathrm{~cm} \mathrm{H}_{2} \mathrm{O}\left(1 \mathrm{~cm} \mathrm{H}_{2} \mathrm{O}\right.$

Xiaomei Zhang

zhangxm322@smu.edu.cn

1 Nanfang Hospital, Southern Medical University, Guangzhou 510515, China

2 School of Nursing, Southern Medical University, Guangzhou 510515, China
$=0.098 \mathrm{kPa}$ ), which can effectively seal the airway, prevent aspiration and reduce the occurrence of complications such as ventilator-associated pneumonia (VAP). Accurately measuring cuff pressure is prerequisite for maintaining cuff pressure within the normal range. Because of its simple operation and intuitive data, the cuff pressure gauge is recommended by the Chinese Thoracic Society (CTS) [3] to measure the pressure of high-volume and low-pressure (HVLP) cuffs. However, in the process of clinical practice, many low cuff pressure phenomena are still found in direct measurement using cuff pressure gauge.In the past, it was mostly attributed to the factors such as sputum suction, 
swallowing, changes in body position and time [4-7]. Earlier study [8] had shown that using an cuff pressure gauge to measure directly with $0 \mathrm{~cm} \mathrm{H}_{2} \mathrm{O}$ before measurement in accordance with the product manual will result in pressure loss, which was mainly reflected in two aspects: one was that a small amount of air escaped when the cuff was disconnected and connected; the second was that the pressure in the cuff transferred to the internal space of the cuff pressure gauge during the measurement, resulting in a decrease in pressure.In order to reduce pressure loss, clinical medical staff improved the device by introducing a three-way tap [9]. When measuring, connect the cuff pressure gauge to the three-way tap, turn off the three-way tap after correction and remove the cuff pressure gauge. This method can effectively avoid the 1-2 $\mathrm{cm} \mathrm{H}_{2} \mathrm{O}$ pressure loss of the cuff during the disconnection and connection of the intermittent measurement, but the main pressure loss caused by transferring from the cuff to the cuff pressure gauge cannot be avoided.

For reasons of cuff pressure loss, the modified cuff pressure measurement method was proposed [10]: connect a three-way tap to the cuff pressure gauge, turn off the three-way tap, inflate the cuff pressure gauge to $32 \mathrm{~cm}$ $\mathrm{H}_{2} \mathrm{O}$ and then connect the cuff for measurement, while another study [11] inflated to $30 \mathrm{~cm} \mathrm{H}_{2} \mathrm{O}$. It can be seen that the modified cuff pressure measurement method has not yet reached a unified consensus of the amount of inflation. The effect of different inflation volume on the accuracy of cuff pressure measurement is still not clear.Therefore, this study combines in vitro experiments and clinical trials to evaluate the effect of different inflation volume on the accuracy of the modified cuff pressure measurement method in different shapes of cuffs. The purpose is to clarify the optimal inflation volume of the modified cuff pressure measurement method, and provide a reference for the correct monitoring of cuff pressure and prevention of complications.

\section{Materials and methods}

\subsection{In vitro study}

The study tools include the followings: Cuff pressure gauge (German VBM Medical Technology Co., Ltd.), endotracheal tube (ETT) of tracheotomy(Smith Medical Instruments (Beijing) Co., Ltd., ETT size: 8.0, cylindrical cuff), ETT of tracheal intubation (Kehui Medical Equipment International Trade (Shanghai) Co., Ltd., ETT size: 8.0, tapered cuff), three-way tap, and extension tube. The cuff pressure gauge is composed of a dial, an inflatable bulb, a release valve and an extension tube. The pressure ranges from 0 to $120 \mathrm{~cm}$ $\mathrm{H}_{2} \mathrm{O}$. It can be inflated by an inflatable bulb and deflated by a release valve.
Check the performance of the instrument before measurement: (1) Check the cuff pressure gauge for air leakage: press the Luer connector with your hand, pinch the inflatable bulb, wait for the cuff pressure to reach $120 \mathrm{~cm} \mathrm{H}_{2} \mathrm{O}$, and keep it for $2-3$ seconds. If the pressure is stable, the performance of the cuff is good, otherwise air leakage occurs; (2) Check the ETT cuff for air leakage: under the premise of ensuring tight connection, connect the three-way tap, extension tube, cuff pressure gauge and ETT. After inflating the cuff to $30 \mathrm{~cm} \mathrm{H}_{2} \mathrm{O}$, observe whether the pointer moves. If it moves, it is not available due to air leakage.

The steps are as follows: a three-way tap and an extension tube are used to connect the cuff pressure gauge and ETT cuff. In order to minimize the effect of the air volume in the extension tube on the measurement results, the length of the extension tube except the connection part is cut to $1 \mathrm{~cm}$ under the premise of ensuring tight connection, convenient operation and avoiding air leakage.The "traditional cuff pressure measurement method"(As shown in Fig. 1-Left, "0 cm $\mathrm{H}_{2} \mathrm{O}$ " displayed on the dial before turning on three-way tap): (1) Inflate the cuff to $28 \mathrm{~cm} \mathrm{H}_{2} \mathrm{O}$ ("initial corrected target value") and turn the three-way tap to a $45^{\circ}$ closed state. (2) Press the release valve to deflate the cuff pressure gauge until the dial shows $0 \mathrm{~cm} \mathrm{H}_{2} \mathrm{O}$, then turn on the three-way tap. (3) Record the value ("actual measured value I") displayed on the dial of the cuff pressure gauge after the pointer stabilizes.The "modified cuff pressure measurement method" (As shown in Fig. 1-Right, e.g "30 $\mathrm{cm} \mathrm{H}_{2} \mathrm{O}$ " displayed on the dial before turning on three-way tap): (1) Inflate the cuff to the initial corrected target value of $28 \mathrm{~cm} \mathrm{H}_{2} \mathrm{O}$ and turn the three-way tap to a $45^{\circ}$ closed state. (2) Press the release valve to deflate the cuff pressure gauge until the dial shows $25 \mathrm{~cm} \mathrm{H}_{2} \mathrm{O}$, then turn on the three-way tap. (3) Record the value( "actual measured value II") displayed on the dial of the cuff pressure gauge after the pointer is stable. (4) Follow the above steps to inflate the cuff pressure gauge until the dial shows $28 \mathrm{~cm} \mathrm{H}_{2} \mathrm{O}, 30 \mathrm{~cm} \mathrm{H}_{2} \mathrm{O}, 32 \mathrm{~cm} \mathrm{H}_{2} \mathrm{O}$, and then connect the ETT for measurement.

\subsection{Clinical study}

This study was a cross-sectional study, patients with artificial airways who were admitted to Neuro-intensive Care Unit (Neuro-ICU) of Nanfang Hospital, Southern Medical University (Guangzhou, China) from July 2020 to September 2020 were selected as study subjects. Inclusion criteria: (1) Patients with artificial airway established by orotracheal intubation or tracheotomy, ETT of tracheal intubation with a tapered cuff or ETT of tracheotomy with a cylindrical cuff; (2) Age of 18-80 years; (3) Using HVLP cuff, ETT size: 7.0-8.5; (4) ETT of tracheal intubation time $\leq 7$ days, ETT of tracheotomy time $\leq 30$ days; (5) All the patients and their family members 


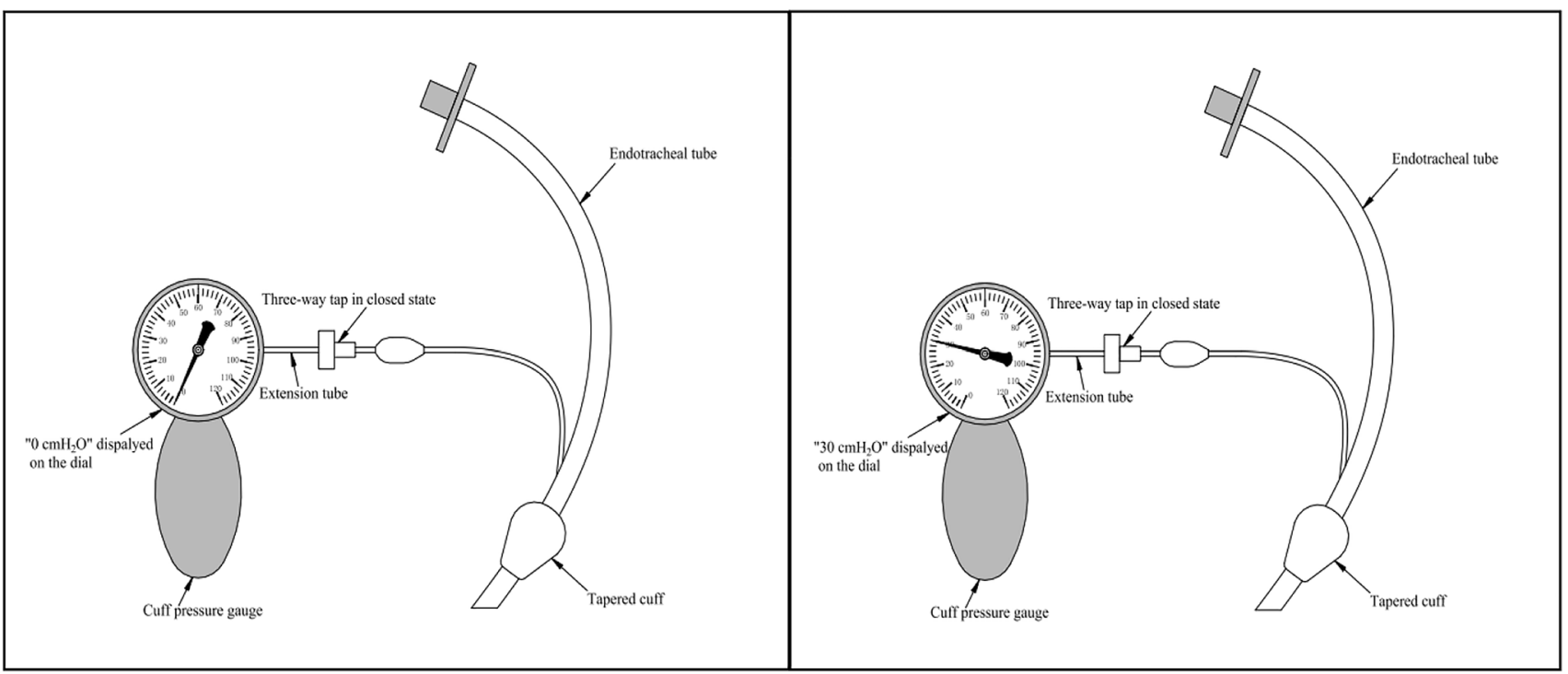

Fig. 1 Schematic diagram of study tools connection (Taking ETT of tracheal intubation with a tapered cuff as an example)-Left: Traditional cuff pressure measurement method (" $0 \mathrm{~cm} \mathrm{H}_{2} \mathrm{O}$ " displayed on

agreed to participate in the study and signed the informed consent form. Exclusion criteria: (1) Patients in prone position ventilation; (2) Leakage of ETT cuff; (3) Patients with contraindication for head of the bed elevation; (4) Pregnant or lactating women; (5) Patients with tracheal injury, inflammation or foreign bodies.

The cuff pressure was measured and corrected after operating factors such as sputum suction, subglottic suction, turning over and other factors that may cause cuff pressure to drop. Patient status during measurement: the head of the bed elevated $30^{\circ}$, the head in neutral position and calm breathing state without coughing, swallowing, agitation and no voluntary movement. The actual measured values and the corrected values were the end-expiratory cuff pressure values. The measurement steps were the same as in vitro study.

This study carried out strict quality control, including the following contents: (1) Both the cuff pressure gauge and ETT cuffs should be checked for air leakage before in vitro experiments and clinical trials; (2) The connection process should be tight to prevent leakage; (3) When reading, keep the line of sight perpendicular to the cuff pressure gauge and flush with the pointer. The researcher and the trained Neuro-ICU nurses shall measure, read and record at the same time. Correct target values and actual measured values were all end-expiratory cuff pressure values in clinical trial; (4) Avoid pulling during the measurement process to inaccurate readings; (5) The patient was measured under calm breathing to eliminate interference from other clinical factors. the dial before turning on three-way tap); Right: Modified cuff pressure measurement method (e.g " $30 \mathrm{~cm} \mathrm{H}_{2} \mathrm{O}$ " displayed on the dial before turning on three-way tap)

\subsection{Ethical considerations}

This study was in accordance with the World Medical Association Declaration of Helsinki-Ethical Principles for Medical Research Involving Human Subjects. Ethical approval was obtained from the Ethics Committee of Nanfang Hospital, Southern Medical University. (Approval Number: NFEC-2020-210).

\subsection{Statistical analysis}

Statistical analyses were performed using SPSS versions 23.0. Measurement data were displayed as the mean and standard deviation $(\bar{x} \pm \mathrm{s})$, intergroup comparisons were conducted by the Student's $t$ test, while intragroup comparisons were analyzed by the Student paired $t$ test. The enumeration data were expressed as number $(n)$ and percentage (\%), and analyzed by Chi-square test or Fisher exact test. The coefficient of variation(CV) evaluated the degree of change of cuff pressure affected by the air volume, and the calculation formula [12]: $\left[\left(P_{\text {max }}-P_{\text {mean }}\right)+\left(P_{\text {mean }}-P_{\text {min }}\right)\right] / 2$. Statistical significance was set at $P \leq 0.05$.

\section{Results}

\subsection{In vitro study}

The cylindrical cuff group and the tapered cuff group were each repeatedly measured 30 cycles, a total of 300 
measurements. When comparing the same shape cuff group, the differences between the actual measured value and the corrected target value in the traditional cuff pressure measurement method and the modified cuff pressure measurement method (measured with $25 \mathrm{~cm} \mathrm{H}_{2} \mathrm{O}, 30 \mathrm{~cm} \mathrm{H}_{2} \mathrm{O}, 32$ $\left.\mathrm{cm} \mathrm{H}_{2} \mathrm{O}\right)$ were statistically significant $(P<0.000)$. When $28 \mathrm{~cm} \mathrm{H}_{2} \mathrm{O}$ was measured, the actual measured value was consistent with the corrected target value. In the traditional cuff pressure measurement method, the pressure loss values of the cylindrical cuff and the tapered cuff were $(3.75 \pm$ $0.31) \mathrm{cm} \mathrm{H}_{2} \mathrm{O}$ and $(4.92 \pm 0.44) \mathrm{cm} \mathrm{H}_{2} \mathrm{O}$, respectively. The ranges of the difference between the actual measured value of the modified cuff pressure measurement method and the corrected target value were $(0-1.07 \pm 0.25) \mathrm{cm} \mathrm{H}_{2} \mathrm{O}$ and
(0-1.23 \pm 0.25$) \mathrm{cm} \mathrm{H}_{2} \mathrm{O}$, respectively. When comparing different shapes of cuffs between the two groups, the actual measured values of the traditional cuff pressure measurement method and the modified cuff pressure measurement method (measured with $25 \mathrm{~cm} \mathrm{H}_{2} \mathrm{O}, 32 \mathrm{~cm} \mathrm{H}_{2} \mathrm{O}$ ) were compared, and the differences were statistically significant $(P$ $<0.05)$. The $\mathrm{CV}$ between the two groups was statistically significant $(P<0.000)$ (Table 1 and Fig. 2$)$.

\subsection{Clinical study}

A total of 30 subjects were included in the clinical study, of which 7 subjects were intubated first, followed by tracheotomy, 18 cases of tracheotomy and 19 cases of tracheal

Table 1 In vitro study: the effect of different inflation volume in different shapes of cuffs on the actual measured values of the modified cuff pressure measurement method

\begin{tabular}{|c|c|c|c|c|c|c|c|}
\hline \multirow[t]{2}{*}{ Cuff shape } & \multirow[t]{2}{*}{$\begin{array}{l}\text { Corrected target } \\
\text { value }\left(\mathrm{cm} \mathrm{H}_{2} \mathrm{O}\right)\end{array}$} & \multirow{2}{*}{$\begin{array}{l}\text { Traditional cuff pressure } \\
\text { measurement method } \\
0 \mathrm{~cm} \mathrm{H}_{2} \mathrm{O}\end{array}$} & \multicolumn{4}{|c|}{$\begin{array}{l}\text { Modified cuff pressure measurement method with different infla- } \\
\text { tion volume }\left(\mathrm{cm} \mathrm{H}_{2} \mathrm{O}\right)\end{array}$} & \multirow[t]{2}{*}{$\begin{array}{l}\text { Coefficient of } \\
\text { variation }(\mathrm{CV})\end{array}$} \\
\hline & & & $25 \mathrm{~cm} \mathrm{H}_{2} \mathrm{O}$ & $28 \mathrm{~cm} \mathrm{H}_{2} \mathrm{O}$ & $30 \mathrm{~cm} \mathrm{H}_{2} \mathrm{O}$ & $32 \mathrm{~cm} \mathrm{H}_{2} \mathrm{O}$ & \\
\hline Cylindrical & 28.00 & $24.25 \pm 0.31$ & $27.32 \pm 0.28$ & $28.00 \pm 0.00$ & $29.03 \pm 0.23$ & $29.07 \pm 0.25$ & $2.41 \pm 0.21$ \\
\hline$t^{\mathrm{a}}$ & & 65.234 & 13.462 & - & -25.167 & -23.028 & \\
\hline$P$ & & 0.000 & 0.000 & - & 0.000 & 0.000 & \\
\hline Tapered & 28.00 & $23.08 \pm 0.44$ & $26.87 \pm 0.37$ & $28.00 \pm 0.00$ & $28.92 \pm 0.37$ & $29.23 \pm 0.25$ & $3.08 \pm 0.25$ \\
\hline$t^{\mathrm{a}}$ & & 61.604 & 16.784 & - & -13.449 & -26.626 & \\
\hline$P$ & & 0.000 & 0.000 & - & 0.000 & 0.000 & \\
\hline$t^{\mathrm{b}}$ & & 11.861 & 5.327 & - & 1.466 & -2.544 & -11.206 \\
\hline$P$ & & 0.000 & 0.000 & - & 0.149 & 0.014 & 0.000 \\
\hline
\end{tabular}

${ }^{\text {a }}$ The comparison between the actual measured value and the corrected target value in the same shape cuff group

${ }^{\mathrm{b}}$ The comparison between the actual measured value of the cylindrical cuff and the tapered cuff

Fig. 2 In vitro experiment/ clinical trial: comparison of the difference between the actual measured value and the corrected target value in different shapes of cuffs

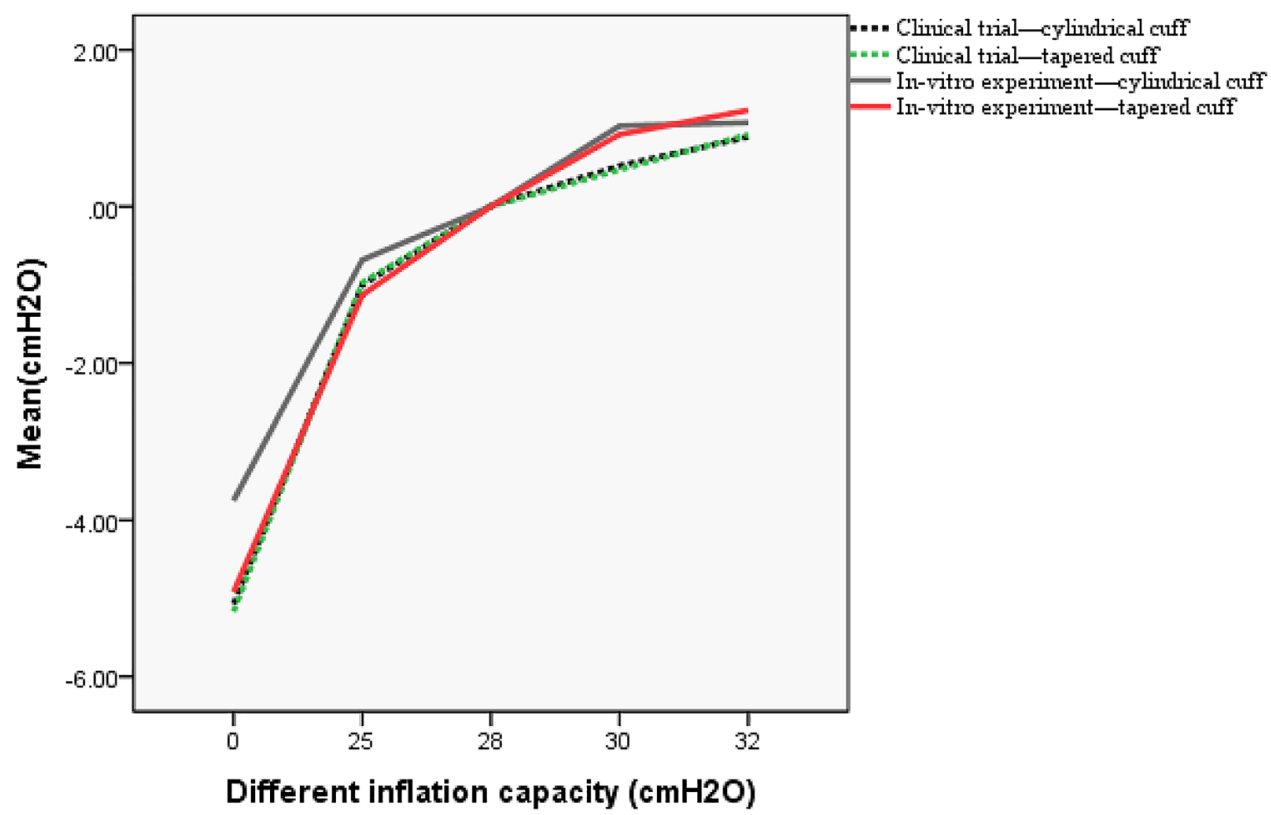


intubation. There were no statistically significant differences in gender, age, model, Acute Physiology and Chronic Health Evaluation II (APACHE II) score, whether mechanical ventilation and whether sedation between the two groups of patients $(P>0.05)$. The baseline data of the two groups were balanced and comparable (Table 2).

Cylindrical cuff group and tapered cuff group were measured 180 cycles and 190 cycles, respectively, for a total of 900 and 950 measurements. When comparing the same shape cuff group, the differences between the actual measured value and the corrected target value in the traditional cuff pressure measurement method and the modified cuff pressure measurement method (measured with $25 \mathrm{~cm} \mathrm{H}_{2} \mathrm{O}, 30 \mathrm{~cm} \mathrm{H}_{2} \mathrm{O}, 32 \mathrm{~cm} \mathrm{H}_{2} \mathrm{O}$ ) were statistically significant $(P<0.000)$. In the traditional cuff pressure measurement method, the pressure loss values of the cylindrical cuff and the tapered cuff were $(5.07 \pm 0.83) \mathrm{cm}$ $\mathrm{H}_{2} \mathrm{O}$ and $(5.17 \pm 0.93) \mathrm{cm} \mathrm{H}_{2} \mathrm{O}$, respectively. The ranges of the difference between the actual measured value and the corrected target value of the modified cuff pressure measurement method were $(0.01 \pm 0.13-1.00 \pm 0.46) \mathrm{cm}$ $\mathrm{H}_{2} \mathrm{O}$ and $(0.00 \pm 0.15-0.97 \pm 0.43) \mathrm{cm} \mathrm{H}_{2} \mathrm{O}$, respectively.
Table 2 Comparison of general data of two groups of patients with different shapes of cuffs

\begin{tabular}{|c|c|c|c|c|}
\hline & \multicolumn{2}{|l|}{ Group } & \multirow[t]{2}{*}{$t / \chi^{2}$} & \multirow[t]{2}{*}{$P$} \\
\hline & cylindrical & tapered & & \\
\hline Gender, (n,\%) & & & - & $1.000^{\mathrm{b}}$ \\
\hline Men & $15(40.54 \%)$ & $16(43.24 \%)$ & & \\
\hline Women & $3(8.11 \%)$ & $3(8.11 \%)$ & & \\
\hline Age, (Years, $\bar{x} \pm s)$ & $51.94 \pm 14.44$ & $56.37 \pm 14.73$ & -0.922 & $0.363^{\mathrm{a}}$ \\
\hline ETT size, $(\mathrm{n}, \%)$ & & & - & $0.427^{\mathrm{b}}$ \\
\hline 7.0 & $1(2.70 \%)$ & $2(5.41 \%)$ & & \\
\hline 7.5 & $1(2.70 \%)$ & $6(16.22 \%)$ & & \\
\hline 8.0 & $8(21.62 \%)$ & $7(18.92 \%)$ & & \\
\hline 8.5 & $8(21.62 \%)$ & $4(10.81 \%)$ & & \\
\hline APACHE II score, (scores, $\bar{x} \pm \mathrm{s}$ ) & $18.61 \pm 7.20$ & $18.63 \pm 5.75$ & -0.009 & $0.993^{\mathrm{a}}$ \\
\hline Whether mechanical ventilation, $(\mathrm{n}, \%)$ & & & - & $0.091^{\mathrm{b}}$ \\
\hline Yes & $9(24.32 \%)$ & $15(40.54 \%)$ & & \\
\hline No & $9(24.32 \%)$ & $4(10.81 \%)$ & & \\
\hline Whether sedation, $(\mathrm{n}, \%)$ & & & - & $0.180^{\mathrm{b}}$ \\
\hline Yes & $4(10.81 \%)$ & $14(37.84 \%)$ & & \\
\hline no & $1(2.70 \%)$ & $18(48.65 \%)$ & & \\
\hline
\end{tabular}

${ }^{\text {a}}$ The Student's $t$ test

${ }^{\mathrm{b}}$ The Fisher exact test

Table 3 Clinical trial: the effect of different inflation volume in different shapes of cuffs on the actual measured values of the modified cuff pressure measurement method

\begin{tabular}{|c|c|c|c|c|c|c|c|}
\hline \multirow[t]{2}{*}{ Cuff shape } & \multirow[t]{2}{*}{$\begin{array}{l}\text { Corrected target } \\
\text { value }\left(\mathrm{cm} \mathrm{H}_{2} \mathrm{O}\right)\end{array}$} & \multirow{2}{*}{$\begin{array}{l}\text { Traditional cuff pressure } \\
\text { measurement method } \\
0 \mathrm{~cm} \mathrm{H}_{2} \mathrm{O}\end{array}$} & \multicolumn{4}{|c|}{$\begin{array}{l}\text { Modified cuff pressure measurement method with different infla- } \\
\text { tion volume }\left(\mathrm{cm} \mathrm{H}_{2} \mathrm{O}\right)\end{array}$} & \multirow[t]{2}{*}{$\begin{array}{l}\text { Coefficient of } \\
\text { variation }(\mathrm{CV})\end{array}$} \\
\hline & & & $25 \mathrm{~cm} \mathrm{H}_{2} \mathrm{O}$ & $28 \mathrm{~cm} \mathrm{H}_{2} \mathrm{O}$ & $30 \mathrm{~cm} \mathrm{H}_{2} \mathrm{O}$ & $32 \mathrm{~cm} \mathrm{H}_{2} \mathrm{O}$ & \\
\hline Cylindrical & 28.00 & $22.93 \pm 0.83$ & $27.00 \pm 0.46$ & $28.01 \pm 0.13$ & $28.52 \pm 0.40$ & $28.89 \pm 0.38$ & $2.98 \pm 0.44$ \\
\hline$t^{\mathrm{a}}$ & & 81.577 & 29.134 & -1.156 & 17.766 & -31.125 & \\
\hline$P$ & & 0.000 & 0.000 & 0.249 & 0.000 & 0.000 & \\
\hline Tapered & 28.00 & $22.83 \pm 0.93$ & $27.03 \pm 0.43$ & $28.00 \pm 0.15$ & $28.47 \pm 0.43$ & $28.92 \pm 0.49$ & $3.05 \pm 0.55$ \\
\hline$t^{\mathrm{a}}$ & & 76.805 & 30.883 & 0.242 & -15.311 & -26.197 & \\
\hline$P$ & & 0.000 & 0.000 & 0.809 & 0.000 & 0.000 & \\
\hline$t^{\mathrm{b}}$ & & 1.651 & -0.963 & 0.947 & 1.075 & -0.767 & -1.270 \\
\hline$P$ & & 0.100 & 0.336 & 0.344 & 0.283 & 0.444 & 0.205 \\
\hline
\end{tabular}

${ }^{a}$ The comparison between the actual measured value and the corrected target value in the same shape cuff group

${ }^{\mathrm{b}}$ The comparison between the actual measured value of the cylindrical cuff and the tapered cuff 
The CV between the two groups was no statistically significant $(P=0.205)$ (Table 3 and Fig. 2).

\section{Discussion}

The guideline [13] recommends continuous cuff pressure monitoring on a conditional basis and regular monitoring with cuff pressure gauges when unconditional [3]. An investigation on the current status of cuff pressure monitoring for nursing staffs in 28 ICUs in 16 hospitals in Guangdong Province [14] showed that the number of nursing staffs who used the cuff pressure gauge accounted for $73.44 \%$. It can be seen that cuff pressure gauge monitoring is still the most widely applied, extensive and relatively objective monitoring technology.

Previous studies [7, 15] applied cuff pressure gauges to directly measure cuff pressure, and found that low cuff pressure was common in clinical practice. In the past, it was mostly attributed to factors such as sputum suction, swallowing, patient position and time. However, this study shows that the direct measurement with $0 \mathrm{~cm} \mathrm{H}_{2} \mathrm{O}$ of traditional cuff pressure measurement can lead to the loss of cuff pressure. In clinical study, the pressure loss values of cylindrical cuff and tapered cuff were $(5.07 \pm 0.83) \mathrm{cm} \mathrm{H}_{2} \mathrm{O}$ and $(5.17 \pm$ $0.93) \mathrm{cm} \mathrm{H}_{2} \mathrm{O}$, respectively, which was consistent with previous research conclusions $[8,11,16,17]$. This is because when the cuff is inflated to $28 \mathrm{~cm} \mathrm{H}_{2} \mathrm{O}$, cuff pressure is equal to the pressure inside the cuff pressure gauge. At this point, close the three-way tap and use the release valve to reduce the cuff pressure gauge to $0 \mathrm{~cm} \mathrm{H}_{2} \mathrm{O}$ before connecting to the cuff, part of the air in the cuff escapes to the internal space of the cuff pressure gauge due to the pressure difference, which resulting in a pressure drop [17]. The reason for the inconsistent pressure loss value may be related to the different cuffs in the shape, material and compliance, and the internal structure of the cuff pressure gauge. In addition, this study showed that the actual measured values of the traditional cuff pressure measurement method were all lower than 25 $\mathrm{cm} \mathrm{H}_{2} \mathrm{O}$. But an in vitro experiment [18] showed that when the cuff pressure was lower than $25 \mathrm{~cm} \mathrm{H}_{2} \mathrm{O}$, all the liquid on the cuff would leak. It can be seen that the traditional cuff pressure measurement method can easily lead to leakage of secretions on the cuffs and increase the risk of aspiration. However, the cuff pressure gauge is inflated to a certain value by the modified cuff pressure measurement method before connecting the cuff can effectively reduce the loss of air in the cuff due to the pressure difference. This study showed that the overall range of difference between the actual measured value and the corrected target value of the modified cuff pressure measurement method was $(0-1.23 \pm 0.25) \mathrm{cm}$ $\mathrm{H}_{2} \mathrm{O}$. The results of the present study further support this conclusion of other study [10]. Therefore, the modified cuff pressure measurement method is recommended for measuring and correcting the cuff pressure during the monitoring period, which can effectively reduce the risk of leakage of secretions from the cuff to the lower respiratory tract due to the instantaneous drop in cuff pressure, which is simple, feasible and worthy of wide application.In order to make up for the small amount of gas leaked during disconnection and connection, the inflation pressure should be $2 \mathrm{~cm} \mathrm{H}_{2} \mathrm{O}$ higher than the corrected target value during each manual measurement [3].

The present study showed that the modified cuff pressure measurement method differed in inflation and the actual measured values were different. In the in vitro experiments, since there was no pressure difference, different shapes of cuffs were measured with $28 \mathrm{~cm} \mathrm{H}_{2} \mathrm{O}$ of the modified cuff pressure measurement method, the actual measured value was consistent with the corrected target value. In clinical trials, when $28 \mathrm{~cm} \mathrm{H}_{2} \mathrm{O}$ was used for measurement, the overall range of difference between the actual measured value and the corrected target value was $(0.00 \pm 0.15-0.01 \pm 0.13) \mathrm{cm}$ $\mathrm{H}_{2} \mathrm{O}$, which may be due to the effect of the patient's breathing [3], and there existed the possibility of a measurement error. In addition, the results of in vitro experiments and clinical trials showed that the modified cuff pressure measurement method (measured with $25 \mathrm{~cm} \mathrm{H}_{2} \mathrm{O}, 30 \mathrm{~cm} \mathrm{H}_{2} \mathrm{O}, 32$ $\left.\mathrm{cm} \mathrm{H}_{2} \mathrm{O}\right)$ had difference ranges of $(0.68 \pm 0.28-1.23 \pm 0.25)$ $\mathrm{cm} \mathrm{H}_{2} \mathrm{O}$ and $(0.47 \pm 0.43-1.00 \pm 0.46) \mathrm{cm} \mathrm{H}_{2} \mathrm{O}$ between the actual measured value and the corrected target value. The closer the inflation volume was to the corrected target value, the closer the actual measured value was to the corrected target value, and the measurement was more accurate. Analysis of the reasons may be related to the application of HVLP cuffs, when the gas capacity in the cuff changes greatly, the pressure change of the cuff is smaller to ensure the safety of the cuff because of the large contact area between the cuff and the tracheal wall clinically [19]. Therefore, in order to improve the accuracy of the measurement, it is advisable to use the modified cuff pressure measurement method to measure.

Cylindrical HVLP cuff is widely used in clinics because of their excellent compliance and large contact area with the tracheal wall, which reduces the pressure on the tracheal mucosa. However, the diameter of the cylindrical cuff after inflation is larger than the inner diameter of the trachea, which is readily forming folds. When the patient is coughing or restless, the secretions on the cuff are prone to leak from the lower respiratory tract and cause aspiration or VAP. While the tapered cuff is recommended to be used for better fitting the patient's airway and reducing the formation of folds in clinical [3]. In vitro experiments revealed that the $\mathrm{CV}$ of the tapered cuff was greater than that of the cylindrical cuff $(3.08 \pm 0.25$ VS $2.41 \pm 0.21, P<0.000)$, which was in accordance with the conclusions of many previous studies 
[20-22]. The reason is that the tapered cuff has a small force area compared with the cylindrical cuff. When the pressure is constant, the smaller the force area is, the greater pressure will be, and the cuff pressure is likely to be too low or too high [17]. So it is necessary to pay attention to the measurement and correction of the tapered cuff in clinical practice. However, there is still some controversy about whether the tapered cuff is better than the cylindrical cuff in preventing complications. A systematic review [23] of 1324 patients in 27 ICUs included in 6 clinical randomized controlled trials pointed out that there was no statistically significant difference in the incidence of hospital-acquired pneumonia(HAP) between the tapered cuff group and the cylindrical cuff group $(\mathrm{OR}=0.97,95 \%$ CI $0.73-1.28, P=0.81)$, and it also had no advantage in reducing the mortality, duration of mechanical ventilation and length of hospital stay.

The main limitation of the present study was that although it had pointed out that the modified cuff pressure measurement method with the actual cuff pressure value as the inflation volume will measure more accurately, the method for predicting the actual cuff pressure value is not clear in clinical practice. Therefore, this study will further explore the effect of nursing operation, time, mechanical ventilation mode and other factors after cuff pressure correction. Aiming to comprehensively predict the actual cuff pressure value, improve the accuracy of cuff pressure measurement, effectively control the cuff pressure within the normal range and prevent complications such as aspiration and VAP.

\section{Conclusion}

Cuff pressure monitoring is an important part of cuff management, and measurement accuracy is closely related to cuff pressure measurement methods. The traditional cuff pressure measurement method can directly cause the pressure to drop, which is easy to cause the leakage of secretions on the cuff and the misjudgment of the cuff pressure by medical personnel. The modified cuff pressure measurement method can effectively reduce cuff pressure loss, and taking the actual cuff pressure value as the inflation volume is the highest measurement accuracy.Tapered cuff is more susceptible to air volume than cylindrical cuff, and medical personnel should pay more attention to its measurement and correction in clinical practice.

Authors contribution Study design: LJX, MC, XMS, XMZ. Recording data: LJX, MQT, TSD. Collate data: LJX, MC. Data analysis: LJX, MC, XMS, XMZ. Writing manuscript: LJX, MC, YW. Reading manuscript: LJX, MC, YW, XMZ.

Funding This work was supported by Dean's Fund Nursing Project of Nanfang Hospital, Southern Medical University, Number: $2020 \mathrm{H} 002$.
Data availability All data needed to evaluate the conclusions in the paper are present in the paper.

\section{Compliance with ethical standards}

Conflict of interest The authors have declared that no conflict of interest exists.

Ethical approval Ethical approval was obtained from the Ethics Committee of Nanfang Hospital, Southern Medical University. (Approval Number: NFEC-2020-210)

Consent to participate The authors agree to participate.

Consent for publication The authors agree to publish.

\section{References}

1. Infectology Group, Respiratory Diseases Branch of Chinese Medical Association. Guidelines for the diagnosis and treatment of hospital-acquired pneumonia and ventilator-associated pneumonia in Chinese adult hospitals (2018 edition). Chin J Tubercul Respir. 2018;41(4):255-80.

2. Bassi G, Ferrer M, Marti J, et al. Ventilator-Associated Pneumonia. Sem Respir Crit Care Med. 2014;35(04):469-81.

3. Infectology Group of Respiratory Branch of Chinese Medical Association. Expert consensus on the management of artificial airway balloon (draft). Chin J Tubercul Respir Med. 2014;37(11):816-9.

4. Kim D, Jeon B, Son J, et al. The changes of endotracheal tube cuff pressure by the position changes from supine to prone and the flexion and extension of head. Korean $\mathbf{J}$ Anesthesiol. 2015;68(1):27.

5. Wu YS, Su GX, Yin YL, et al. The influence of 4 kinds of clinical factors on artificial airway balloon pressure. Chin J Nurs. 2017;52(08):934-7.

6. Athiraman U, Gupta R, Singh G. Endotracheal cuff pressure changes with change in position in neurosurgical patients. Int $\mathrm{J}$ Crit Illn Inj Sci. 2015;5(4):237-41.

7. Alzahrani AR, Al Abbasi S, Abahoussin OK, et al. Prevalence and predictors of out-of-range cuff pressure of endotracheal and tracheostomy tubes: a prospective cohort study in mechanically ventilated patients. BMC Anesthesiology. 2015;15(1).

8. Huang L, Zhang LF, Meng LY, et al. Analysis of the causes of pressure loss in the tracheal tube cuff caused by intermittent pressure measurement with a handheld manometer. Chin J Nurs. 2016;51(12):1501-3.

9. Yu J, Li ZZ, Ren ML, et al. Application of three-way connection in air bag pressure monitoring in patients with artificial airway. Chin J Mod Nurs. 2019;25(16):2011-4.

10. Huang L, Zhang LF, Meng LY, et al. Application study of improving the method of cuff pressure measurement to prevent ventilatorassociated pneumonia. Chin Crit Care Med. 2019;31(8):1024-7.

11. Lin YX, Lin D, Chen BQ, et al. Experimental study on the intermittent measurement of air bag pressure deviation by air bag pressure gauge. Chin Crit Care Med. 2014;26(05):347-50.

12. Monsel A, Lu Q, Le Corre M, et al. Tapered-cuff endotracheal tube does not prevent early postoperative pneumonia compared with spherical-cuff endotracheal tube after major vascular surgery: a randomized controlled trial. Anesthesiology. 2016;124(5):1041-52. 
13. Klompas M, Branson R, Eichenwald EC, et al. Strategies to prevent ventilator-associated pneumonia in acute care hospitals: 2014 update. Infect Control Hosp Epidemiol. 2014;35(S2):S133-54.

14. Wu QM, Wang JJ, Zhang XX, et al. Investigation and countermeasures on the status quo of cognition of artificial airway balloon pressure monitoring among ICU nurses in 16 hospitals in Guangdong Province. Chin J Modern Nurs. 2015;26:3165-7.

15. Nseir S, Rodriguez A, Saludes P, et al. Efficiency of a mechanical device in controlling tracheal cuff pressure in intubated critically ill patients: a randomized controlled study. Ann Intensive Care. 2015;5(1):54.

16. Nazari R, Boyle C, Panjoo M, et al. The changes of endotracheal tube cuff pressure during manual and intermittent controlling in intensive care units. Iran J Nurs Midwifery Res. 2020;25(1):71.

17. Asai S, Motoyama A, Matsumoto Y, et al. Decrease in cuff pressure during the measurement procedure: an experimental study. $\mathrm{J}$ Intensive Care. 2014;2(1):34.

18. Huang L, Chen Y, Zhang LF, et al. Study on the effect of two pressure measurement methods on the airway closure effect of cuffs with different shapes. Chin J Nurs. 2019;54(2):274-6.

19. Kumar CM, Seet E, Van Zundert TCRV. Measuring endotracheal tube intracuff pressure: no room for complacency. J Clin Monitor Comput. 2020
20. Bowton DL, Hite RD, Martin RS, et al. The impact of hospital-wide use of a tapered-cuff endotracheal tube on the incidence of ventilator-associated pneumonia. Respir Care. 2013;58(10):1582-7.

21. Monsel A, Le Corre M, Deransy R, et al. Modification of tracheal cuff shape and continuous cuff pressure control to prevent microaspiration in an ex vivo pig tracheal two-lung model. Crit Care Med. 2017;45(12):e1262-9.

22. Kim H, Lee Y, Kim E, et al. Comparison of the endotracheal tube cuff pressure between a tapered- versus a cylindrical-shaped cuff after changing from the supine to the lateral flank position. Canad J Anesth. 2015;62(10):1063-70.

23. Maertens B, Blot K, Blot S. Prevention of ventilator-associated and early postoperative pneumonia through tapered endotracheal tube cuffs. Crit Care Med. 2018;46(2):316-23.

Publisher's Note Springer Nature remains neutral with regard to jurisdictional claims in published maps and institutional affiliations. 